the extent of maltreatment, neglect, and underfunding that can carry on behind high walls. Large institutions, however devised, soon regress into the economies of scale, stigmatisation of patients and staff, and a dreary stultifying of the spirit of research. The "bag ladies" and vagrants of the 1980 s are no better, but could justifiably be seen as consequent to high unemployment as much as to community care. It should also be noted that the needs of those discharged from long term care have in general been well met. ${ }^{23}$ Such patients must not be confused with the younger, impoverished, "new long stay" patients who dominate public concern. The underfunding of the NHS has particularly deprived them of the acute hospital beds, the well staffed medium term hostels, and the community support teams required for their varying care needs. Likewise, the lack of community mental health orders to ensure continued outpatient treatment has undermined the ability of families or psychiatric professionals to cope outside a hospital setting.

No one denies that some patients will need long term care, but barracks on a hillside are too easily erected. I would suggest that a "community biased" approach is what most patients prefer, ${ }^{3+}$ and that by continuing to expose chronic mental illness to the oxygen of public concern attitudes and resources can be changed. Small specialised units for patients with unresponsive schizophrenia, brain damage, or dementia should be based on high staffing and multidisciplinary (nursing, psychological, behavioural, medical, psychopharmacological) research. Professor Kendell's "mental health campus" sounds alluring but has all the isolationist overtones of what this journal's first editor, Andrew Wynter, called "brick and mortar humanity." ${ }_{+}$

T H TURNER

Department of Psychological Medicine,

St Bartholomew's Hospital,

London EC1A 7BE

1 Kendell RE. The future of Britain's mental hospitals. $\mathrm{Br}$ Med $\mathcal{F}$ 1989;299:1237-8. (18 November.)

2 Jones K, Robinson M, Golightley M. Long-term psychiatric patients in the community. Br f Psychiatry 1986;149:537-40. 3 Bell J, Cremona A, Hallstrom C. Long-term psychiatric patients in the community. Br $\mathcal{A}$ Psychiatry 1987;151:275.

4 Abrahamson D, Brenner D. Do long stay psychiatric patient want to leave hospital? Health Trends 1982;14:95-7.

5 McCandless P. "Build! Build!" The controversy over the care of the chronically insane in England, 1855-1870. Bull Hist Med 1979;53:553-74.

SIR, - I welcome Professor R E Kendell's timely leader on the process of psychiatric hospital rundown and the provision of replacement services. The research team at Friern Hospital, to which he refers, is unique in carrying out a long term evaluation of the provision or replacement services in north London for over 900 patients (funded by both North East Thames Regional Health Authority and the Department of Health). Along with other researchers we agree that there are several groups of patients whose needs are not and will not be met by acute and community based services alone. ${ }^{2}$ These are the elderly demented and behaviourally disturbed, the mentally impaired and psychotic, patients who are brain damaged or psychotic and likely to assault people, and those chronic schizophrenic patients who are vulnerable to neglect and exploitation. Gudeman and Shore have estimated that there are at least 15 patients per 100000 population who cannot be adequately cared for in community facilities. "Such patients will continue to require the provision of asylum, whether or not this is provided within asylums.

For those patients who are being discharged we find it useful to distinguish five groups: new long stay patients with over one year in hospital ("accumulation"), "old long stay" patients, "graduate elderly" patients with an original diagnosis of a functional psychosis but who have developed definite cognitive impairment or physical frailty over time, patients with an admis- sion diagnosis of dementia, and short stay patients who are admitted frequently ("revolving door" patients). All five groups are facing service reprovision: not all are currently served poorly in the community. Of the 161 patients we have followed up one year after discharge, only three were untraceable, and there have been no suicides or imprisonments (D Dayson, 4th annual TAPS conference, 1989). There were no overall changes after discharge (compared with a matched group of patients remaining in hospital) in the discharged patients' mental state, social behaviour, or social networks; but the leavers showed improvement in their daytime activities and commented more favourably about their accommodation. These results lead us to suspect that concern about the inadequacies of community care relates mainly to the "revolving door" group.

Finally, the cost effectiveness study carried out by the personal social service research unit at the University of Kent suggests that the total average costs of community based services for the first 145 patients discharged are little different from the cost of hospital care. It is clear that such empirical data should lead and not follow policy and planning decisions, and we welcome Professor Kendell's call for controlled studies of hospital rundown to be given a high priority.

GRAHAM THORNICROFT

Team for the Assessment of Psychiatric Services,

Friern Hospital,

Friern Hospital,

1 Kendell RE. The future of Britain's mental hospitals. Br Med 7 1989;299:1237-8. (18 November.)

2 Talbott J. The need for asylum, not asylums. Hospital and Community Psychiatry 1984;35:208-9.

Gudeman J, Shore M. Beyond deinstitutionalisation. $N \mathrm{Engl} f$ Med 1984;311:832-6.

4 Bachrach L. Deinstitutionalisation: what do the numbers mean? Hospital and Community Psychiatry 1986;37:118-21.

SIR, - I hope that Professor R E Kendell's editorial' presages a return of interest by the BMA in the worsening plight of former psychiatric patients, but I would have preferred Professor Kendell to have traced the history of the present catastrophe further back to recognise the role of the postwar generation of doctors and nurses who introduced liberal changes before the use of chlorpromazine.

The Mental Health Act 1959 emphasised the desirability of community treatment. Enoch Powell, the minister for health whose "optimistic humanitarian zeal" some took for political expediency, based his plans for reducing hospitals on the observations by Tooth and Brooke. ${ }^{2}$ The Glenside Hospital quinquennial population surveys from 1960 onwards continued to comment on the dangers of running down hospital beds without providing other facilities. In response to the 1964 survey Magnus described "the new chronic" patient ${ }^{5}$ and the 1980 survey concluded that these patients are still with us. ${ }^{6}$ After 20 years the need for accommodation outside hospitals is still urgent.

In 1976 the Bristol Industrial Therapy Housing Association proposed an architect designed campus development of 50 places, with various types of accommodation, to provide trial training and show the abilities of the tenants. Money was available through the housing corporation, and a site was approved in principle by the district health authority. A campus similar to that suggested by the Scottish working party on the care of psychiatric patients was described at the annual general meeting of Mind in 1977. Its design was to show the type of accommodation former patients might choose and the most appropriate accommodation for new chronically ill patients - that is, the design of a modern asylum.

The scheme was rejected by the district health authority after four years of silence, not entirely because "politicians and administrators responsible for the deinstitutionalisation policies generally regarded psychiatrists' pleas for control trials either as an expensive irrelevancy or as a covert attempted sabotage." The hospital medical staff also considered that the scheme was inappropriate to their needs. Perhaps part of the reason that the offer of the site was withdrawn was that subsequently it was sold for housing development for $£ 2 \cdot 5 \mathrm{~m}$ (none of which was allocated to psychiatry).

Up to now it seems that medical influence has been weak and that we have allowed ourselves to be forced into an attractive, untried, and politically motivated course of action. Media personalities such as Esther Rantzen and Marjorie Wallace have been supportive and sympathetic, but doubts such as those reflected by Frank Field, chairman of the Commons social services committee, requesting an inquiry into the Maudsley community care trial and programmes such as World in Action (20 November) shake public confidence. Are we getting it wrong?

I wish the Scottish working party well.

DONAI. F EARLY

Bristol BS8 3LE

1 Kendell RE. The future of Britain's mental hospitals. Br Med 1989;299:1237-8. (18 November.)

2 Tooth GC, Brooke EM. Trends in the mental hospital population and their effect on future planning. Lancet 1961;i:710-3.

3 Cooper $A B$, Early DF. Evolution in the mental hospital. Br.Med f 1961;i:1600-3.

+ Magnus RV. The new chronics. Br f Psychiatry 1967;113:555.

5 Early DF, Nicholas $M$. Two decades of change: Glenside Hospital population surveys 1960-80. Br Med f 1981;282 1446-9.

6 Field $\mathrm{F}$. Trial release of mental patients set to continue. Hospital Doctor 1989 Nov 23:3 (cols 1, 2).

SIR, - In his article on the future of Britain's mental hospitals Professor R Kendell stated that only the North West Thames Regional Health Authority has incorporated a planned evaluation into its closure policies.' Not so; since 1988 the South East Thames region has been funding an independent prospective evaluation of the closure of Cane Hill Hospital by the National Unit for Psychiatric Research and Development, and an interim report is available. ${ }^{2}$ We are also aware of several other regionally funded evaluations due to start in the near future.

The amount of research being conducted into this important issue is still inadequate, but this is not always the fault of the authorities. Research proposals from medical institutions have too often been based on the model of the randomised controlled drug trial, a model of limited application to evaluating new forms of service organisation.

In addition, academic bodies have been slow to recognise and acknowledge the importance of conducting research that is relevant to the needs of policy makers and service planners. As a result these bodies have not been successful in attracting funds from such sources. As well as outcome measures, policy makers also need information about the process of service development and implementation, which is lacking in most evaluation protocols.

J LINDESAY P CLIFFORD

National Unit for Psychiatric Research and Development, Lewisham Hospital London SE13 $6 \mathrm{LH}$

1 Kendell RE. The future of Britain's mental hospitals. Br. Hed 7 1989;299:1237-8

2 Cane Hill Research Team. Evalualing the closure of Cane Hill Hospital. London: National Unit for Psychiatric Research and Development, 1989. (Interim report.

\section{Community pharmacies and prevention of AIDS among injecting drug misusers}

SIR,-The potential role of pharmacies in the prevention of AIDS among injecting drug users' is shown by the New Zealand needle and syringe exchange scheme, which has been operating successfully since May 1988 . 